through repetition proved to be easier than response substitution for Group $3(T=0, N=10, p<.01)$.

It seems clear that if learning through substitution is equivalent to leaming repetitiously, then the second group should have shown the same amount of positive transfer as the first. Since they did not, it may be concluded that the marginal advantage provided by frequency was cancelled out by the presence of practice in the learning of the replacement list. Furthermore, when the interference of partially learned responses is added to the absence of repetition, performance significantly deteriorates. Accordingly, the noncontinuity standpoint must be categorically rejected.

\section{ADDENDUM}

There have been many studies on one-trial learning carried forth in our laboratory. It seemed most profitable to abstract the findings as one separate appendage to the main body of this article, as opposed to submitting a host of lengthy papers to a group of weary editors.

First, we inquired as to whether it was possible to use Rock's substitution procedure in such a way as to permit the intrusion of old, partially learned responses. It was reasoned that if the order of a list of paired associates is held constant, then the response item of a deleted pair should subsequently be elicited by the position which it had previously occupied in the list. This would allow it to compete with the recall of a newty formed connection. Accordingly, an experiment was conducted in which the learning of a repetition list was compared to that of a replacement list, keeping a fixed order of presentation. As a result, learning through repetition was significantly easier.

Secondly, it was difficult to support the continuity position when using the replacement paradigm with a group of rapid learners. However, it was found that frequency provided a decided advantage for these very same Ss when the task was made harder by merely increasing the length of the list.

Finally, the prompting method has been found to be sensitive to small differences between repetition and substitution which cannot be detected using the method of aided recall.

In conclusion, noncontinuity results seem to be based upon a peculiar combination of events, namely, subjecting rapid leamers to a menial task, varying the order of pairs from trial to trial, and using the method of aided recall. When these conditions are not met, the facilitative effects of frequency emerge.

\section{REFERENCE}

ROCK. I. The role of repetition in associative learning. American Joumal of Psyctoolozy, 1957, 70, 186-193.

\section{NOTES}

1. The interference of prior learnins was not poseible in the Rock abstitution procedure. This is partially because the stimuli required to elicit the partially karned responses were no longer present. In addition. the respones could not be selected out on the basis of their previous position whin the list, because the order of the pairs was varied from irial to trial.

2. In order to overcome the possible criticism that the second repetition list may have been easier than the first, it was randomly chosen from a pool of three different lists.

\title{
An attempt to relate test anxiety and Palmar Sweat Index
}

\author{
STEVEN B. SCOTT and MARC KESSLER. University of \\ Nebraska, Lincoln, Nebr. 68508
}

Forty-seven female Ss completed the Mandler-Sarason Test Anxiety Scale (MSTAS), a rating of apprehension in an experimental situation, and were administered the Palmar Sweat Index (PSI), in the experimental situation. Self-ratings of apprehension and MSTAS were significantly correlated, but neither of these were found to correlate with PSI. Items from MSTAS asking about sweating also were not correlated with PSI. Results were discussed in terms of the criticisms of previous attempts at relating verbal and nonverbal indices of anxiety.

Much interest has been evident recently in the relationship between self-report indices of anxiety and measures of physiological emotionality or arousal. With the exception of a study by Haywood \& Spielberger (1966) most of this work has failed to demonstrate any relationship between the two variables (Katkin, 1965; McGuigan, Calvin, \& Richardson, 1957; Winter, Ferreira, \& Ransom, 1965). In discussing factors which may contribute to the difficulty in obtaining such a relationship Katkin suggests that "In order to elicit differential physiological responses from subjects who are presumed to differ in 'reactive anxiety' as measured by the Manifest Anxiety Scale it would appear necessary to elicit differential levels of apprehension from high anxiety and low anxiety subjects [p. 332]." Such differences in apprehension level would therefore seem to be a prerequisite to evaluating the possible relationship between the two measures.

Further, McGuigan et al suggest that the lack of correlation between the verbal and physiological indices may arise because of the different aspects of anxiety tapped by each. They point out that the physiological measures frequently employed, such 
as the Palmar Sweat Index (PSI) may be appropriate measures only where anxiety is of a temporary or situational nature while the Taylor Anxiety Scale (TAS), which is the most commonly used self-report index, may reflect a more stable or permanent characteristic of personality. Correspondence between these two aspects of anxiety could be highly imperfect. A possible solution to this problem would be to use a self-report index designed to estimate situation-specific anxiety and to obtain the physiological measure in that situation. Such an index is the Mandler-Sarason Test Anxiety Scale (MSTAS) which was designed to measure anxiety under test or examination conditions (Mandler \& Sarason, 1952; Sarason \& Gordon, 1953).

The purpose of this study was to reexamine the relationship between a self-report index of anxiety and an estimate of physiological arousal or emotionality, taking into consideration the explanation offered by Katkin and that of McGuigan et al for previous failures to find a correlation between these variables. More precisely, it was expected that a substantial positive correlation would be found between the situationspecific self-report index of anxiety and a physiological estimate of sweating when Ss differing on the anxiety index could also be shown to differ in degree of felt apprehension.

\section{SUBJECTS}

Forty-seven female volunteers from an introductory psychology course served as Ss for this experiment.

The MSTAS was administered (as part of an earlier, unpublished study by the junior author) to all members of the introductory psychology classes at the beginning of the semester in which the present experiment was conducted. Scores on this index were available for each of the Ss taking part.

The PSI was individually administered to each S using a constant-pressure finger-printing device together with the improvements in the technique suggested by Haywood \& Shoemaker (1963) and Brutten (1959). A rating of the degree of apprehension which each $S$ felt in the immediate experimental situation was also obtained. These ratings were made on a 10-point scale ranging from "none" (0) to "moderate" (10).

\section{PROCEDURE}

An attempt was made to induce mild apprehension in all Ss by telling them that the experiment was designed to obtain a personality test estimate of their "social competentness" which was defined as their ability to establish and maintain interpersonal relationships. The importance of such skills was stressed and $S$ was then told that the results would be discussed with her later. A personality test booklet and answer sheet were placed in clear view of S following which the PSI and the rating of apprehension were obtained.

\section{RESULTS}

The PSI prints were independently rank ordered by each $\mathrm{E}$. The Spearman rank correlation between these orderings was $.94(\mathrm{p}<.01)$ indicating that there was a sufficiently high communality between raters so that subsequent calculations could be performed using either set of rankings.

The ratings of apprehension were found to be significantly related to MSTAS scores (rho $=.44, p<.05$ ) providing evidence that high and low anxiety $\mathrm{Ss}$, as measured by the MSTAS, did not report different levels of apprehension in the experimental situation.
The rank order correlation between the MSTAS scores and the PSI prints was -.18 which indicates a nonsignificant inverse relationship between the two measures of anxiety. The MSTAS items which asked specifically about sweating were then scored individually to see if there was any relationship between a verbal report of sweating and the PSI. A cross-break analysis was performed on the resulting frequency data and $x^{2}$ was not significant. The ratings of apprehension were also unrelated to the PSI (rho $=.05)$.

\section{DISCUSSION}

The present study failed to find a relationship between the PSI and the MSTAS, or between the PSI and the rating of felt apprehension in the experimental situation. A relationship was found between the MSTAS and the rating of felt apprehension. These results fail to support the notions of either Katkin or McGuigan et al regarding previous failures to find such a relationship and provide evidence that these two types of measures cannot be used interchangeably. It appears that Ss respond to verbal questioning about their state of anxiety in a manner different from, and inconsistent with, the sweat index but consistent with other verbal measures. Further, Ss do not appear to be accurate reporters of their physiological states (at least as far as sweating is concerned).

The study does not intend to leave the impression that verbal and physiological measures of anxiety are never related. It is quite possible that individuals may be more accurate reporters of their physiological states at levels of arousal more extreme than those used in this study. Nor has any attempt been made here to provide a solution to the issue of which measure is a "better" index of anxiety. It is sugested that such a solution might best be obtained by specifying the behaviors relevant to one's theoretical use of the construct, determining the relationship of both types of measures to these behaviors and adopting that index most consistent with both the theory and its behavioral predictions.

\section{REFERENCES}

BRUTTEN, E. J. Colorimetric measurement of anxiety: $A$ clinical and experimental procedure. Speech Monograph, 1959, 26, 282-287.

HAYWOOD, H. C, \& SHOEMAKER, D. J. Measurement of palms sweating: Effect of repeated measurement from the same area. Journal of Psychology, 1963, 55, 363-369.

HAYWOOD, H. C., \& SPIELBERGER, C. D. Palmar sweating as a function of individual differences in manifest anxiety. Journal of Personality \& Social Psychology, 1966, 3, 103-10S.

KATKIN, E. S. Relationship between manifest anxiety and two indices of autonomic response to stress. Journal of Personality \& Social Psycholozy, 1965, 2, 324-333.

MANDLER, G., \& SARASON, S. B. A study of anxiety and learning Journal of Abnormal \& Social Psychology, 1952, 47, 166-173.

McGUIGAN, F., CALVIN, A., RICHARDSON, E. Manifest anxiety palmar perspiration index, and stylus maze-learning. American Journal of Psychology, 1959, 72, 434-438.

SARASON, S. B., \& MANDLER, G. Some correlates of test anxiety. Joumal of Abnormal \& Social Psycholozy, 1952, 47, $810-817$.

SARASON, S. B., \& GORDON, E. M. The test anxiety questionnaire: Scoring norms. Journal of Abnormal \& Social Psychology, 1953, 48, 447-448.

WINTER, W. O., FERREIRA, J. R., \& RANSOM, R. Two measures of anxiety: A validation. Journal of Consulting Prychology, 1963, 27, $525 \cdot 531$. 